\title{
Multidose intramuscular allogeneic adipose stem cells decrease the severity of canine atopic dermatitis: A pilot study
}

\author{
Nathaly Enciso ${ }^{1,2}$, José Amiel ${ }^{1}$, John Pando ${ }^{3}$ and Javier Enciso ${ }^{1}$
}

\author{
1. Laboratorio de Cultivo Celular e Inmunología, Universidad Científica del Sur, Lima, Perú; 2. Departamento de \\ Bioquímica y Biología Molecular, Facultad de Veterinaria, Universidad Complutense de Madrid, Madrid, Spain; \\ 3. Department of Cytometry, Institute of Cell Therapy. CRIOCORD. Lima. Peru. \\ Corresponding author: Javier Enciso, e-mail: jenciso@cientifica.edu.pe \\ Co-authors: NE: nathenci@ucm.es, JA: jamielperez@gmail.com, JP: jpando@ictc-peru.com \\ Received: 15-07-2019, Accepted: 30-09-2019, Published online: 08-11-2019
}

doi: www.doi.org/ 10.14202/vetworld.2019.1747-1754 How to cite this article: Enciso N, Amiel J, Pando J, Enciso J (2019) Multidose intramuscular allogeneic adipose stem cells decrease the severity of canine atopic dermatitis: A pilot study, Veterinary World, 12(11): 1747-1754.

\begin{abstract}
Aim: The aim of this pilot study was to evaluate the therapeutic and safety performance of an intramuscular treatment protocol of multidose of allogeneic adipose stem cells (ASCs) isolated, characterized, and expanded ex vivo from a healthy canine donor.

Materials and Methods: Twelve dogs diagnosed with canine atopic dermatitis (CAD) were intramuscularly treated with $0.5 \times 10^{6}$ of cryopreserved ASCs from a healthy immunized young canine Ehrlichia canis free donor weekly for 6 weeks. Treatment efficacy was evaluated by the pruritus index and the CAD Lesion Index (CADLI) test. Safety and adverse effects were determined by injection site reaction, weight, blood chemistry, liver function, and whole blood count.
\end{abstract}

Results: Canine ASCs obtained from a donor met the minimum qualities required for this type of cells and showed viability of $90 \%$ after thawing. The efficacy of the CADLI score and the pruritus index in 12 dogs with atopic dermatitis was statistically significant efficacy. No adverse reactions were observed at the intramuscular application site, or in relation to animal weight, blood cell populations, or liver and renal function.

Conclusion: These results suggest that intramuscular administration of cryopreserved ASCs to dogs with atopic dermatitis is a promising cellular therapeutic product for the relief of the symptoms of this disease; however, the duration of the effects obtained with this dose and with other doses should be evaluated, as well as possible immune reactions. As far as we know, this is the first report of the use of multiple intramuscular doses cryopreserved ASCs to treat atopic dermatitis.

Keywords: adipose stem cells, allogeneic stem cells, canine atopic dermatitis, cellular therapy.

\section{Introduction}

Canine atopic dermatitis (CAD) is a common, genetically predisposed inflammatory and pruritic allergic skin disease with characteristic clinical features $[1,2]$, having a prevalence of $20-30 \%$ [3]. In terms of origin, this disease is complex and multifactorial and involves genetic factors [4,5], immune dysregulation, allergic sensitization, skin barrier defects, cutaneous microbiome, and environmental factors [6-8]. The pathogenesis of canine and human atopic dermatitis is not fully understood [9]. In humans, some authors consider it to be a systemic Th2-dependent disease [10], while for others, it is primarily a chronic skin inflammation [11]. Similarly, CAD is considered as an inflammatory disease associated with an aberrant Th2 pattern immune reaction [12]. For this reason, the criteria for diagnosis are based on signs established in clinically recognized guidelines [13]. Given

Copyright: Enciso, et al. Open Access. This article is distributed under the terms of the Creative Commons Attribution 4.0 International License (http://creativecommons.org/licenses/by/4.0/), which permits unrestricted use, distribution, and reproduction in any medium, provided you give appropriate credit to the original author(s) and the source, provide a link to the Creative Commons license, and indicate if changes were made. The Creative Commons Public Domain Dedication waiver (http://creativecommons.org/ publicdomain/zero/1.0/) applies to the data made available in this article, unless otherwise stated. the complex and multifactorial nature of CAD, treatment differs in overtime and geographically. Several randomized controlled clinical trials, as well as systematic reviews, have proposed a choice of prospective drugs that can benefit patients with CAD [14-16], who are also often treated with allergy immunotherapy [17].

Recent clinical studies have shown that CAD treatment has mainly been based on the concept of T-cell immune dysregulation as a major immunological deficiency in atopic dermatitis. Therefore, the current treatment includes agents involving cytokine modulation and/or growth factor receptor expression $[18,19]$. Taking this into account, it has been proposed that blocking chemokine receptor antagonists and/or drugs involved in the inhibition of T-cell activation might have a beneficial effect on CAD [20,21], although short- and long-term side effects still remain an issue $[22,23]$. On the other hand, the use of mesenchymal stem cell (MSC) therapy, especially bone marrow-derived MSCs (BM-MSCs) and adipose stem cells (ASCs), has mainly been supported by the particular traits of these cells, including cell renewal, differentiation, and production/release of a vast array of growth factors, cytokines, and other types of mediators of cell function $[24,25]$. Furthermore, the use of 
allogeneic MSC has shown to be effective and safe in canine diseases [26]. In addition, adult MSCs exhibit attractive immunomodulatory properties in degenerative diseases in animals [27]. This is the case of ASCs, a type of MSC, which in addition to the cellular and molecular traits of BM-MSC, exhibits robust immunosuppressive activity, mediated by induction of the production of Tregs [28] and the selective release of several types of growth factors [29-33].

Therefore, according to the cellular, molecular, and immunomodulatory properties of ASCs, we aimed to evaluate the therapeutic and safety performance of an intramuscular treatment protocol of multidose of allogeneic ASCs in the treatment of atopic canine dermatitis.

\section{Materials and Methods}

\section{Ethical approval and Informed consent}

Licensed veterinary clinicians conducted all the animal procedures. The protocols were approved by the Universidad Científica del Sur's Ethics Committee from Lima, Peru (approval reference number 0042013), and written informed consent was obtained from the owners.

\section{Patients}

Twelve dogs with a clinical diagnosis of atopic dermatitis were enrolled in the study for 6 weeks. The patients were between 1 and 3 years of age and were determined to be healthy on physical examination. Before the study, routine serum chemistry and hematology evaluations were performed to ensure overall systemic health. The diagnosis of atopic dermatitis was based on the clinical history, compatible clinical signs, and exclusion of other pruritic skin disease and met the criteria established by Favrot et al. [13]. The patients had not received antihistamines, glucocorticoids, and cyclosporine treatment during 2, 4, and 8 weeks, respectively, before the study.

\section{Characteristics of the cell product for infusion Isolation of ASCS}

Considering the efficiency in obtaining high cell counts and minimal induced morbidity during cell collection [34], it was decided to use the omentum adipose tissue as a source of ASCs.

Tissue sample $(5 \mathrm{~g})$ from omental fat deposits was obtained from a donor dog, clinically healthy female, mongrel, 1 year old, $8 \mathrm{~kg}$ of weight that met the full annual immunization program, including canine distemper, canine parvovirus, parainfluenza, adenovirus type 2, canine coronavirus, Leptospira, and being Anaplasma, Dirofilaria, Lyme, and Ehrlichia canis free using a SNAP 4Dx Plus test (Idexx, Westbrook, United States). In addition, a chromatographic test was performed previously to rule out the presence of E. canis in blood. The fat deposits were obtained using a standard surgical procedure under anesthesia with intravenous xylazine/ketamine $(1 / 10 \mathrm{mg} / \mathrm{Kg}$ body weight). The donor's owner provided informed consent allowing the use of extracted tissue for research purposes.

The samples were placed in conical centrifuge tubes (FALCON, Thermo Fisher Scientific, Waltham, Massachusetts, USA) containing $25 \mathrm{~mL}$ of Dulbecco's Modified Eagle's Medium (DMEM) (Sigma-Aldrich, St. Louis MO, USA) containing $100 \mathrm{U} / \mathrm{ml}$ penicillin/streptomycin/amphotericin (Millipore, Merck KGaA, Darmstadt, Germany) and sent to the Good Manufacturing Practice facility at the university for processing.

Adipose tissue samples were washed with phosphate buffer solution (PBS) to eliminate blood clots and were then cut and incubated in a PBS containing $1 \mathrm{mg} / \mathrm{ml}$ (Sigma-Aldrich, St. Louis MO, USA) of collagenase type I and 1\% of antibiotic (penicillin, streptomycin, and amphotericin, Millipore) for $1 \mathrm{~h}$ at $37^{\circ} \mathrm{C}$ with slight continuous agitation in a shaker. At the end of the incubation period, a solution containing 10\% fetal bovine serum (FBS; Gibco, Thermo Fisher Scientific, Waltham, Massachusetts, USA) in DMEM was added to stop the collagenase reaction. Afterward, it was filtrated through a cell strainer of $100 \mu \mathrm{m}$ and was centrifuged in at $800 \mathrm{RPM}$ (Boeco C28A, Germany) for $5 \mathrm{~min}$. The cell pellet, containing few native ASCs, was saved and transferred in culture flasks (Nunc, $75 \mathrm{~cm}^{2}$ ) with DMEM, 10\% FBS and $1 \%$ penicillin-streptomycin (Sigma-Aldrich, St. Louis MO, USA).

The cells were cultured in a humidified incubator at $37^{\circ} \mathrm{C}$ at $5 \% \mathrm{CO}_{2}$. After 3 days, the wells were washed 3-4 times with PBS and the medium was recharged. Cells in the developing adherent layer were cultured for 9-12 days, changing the culture medium every 3 days. After reaching $80 \%$ of cell confluence in the developing adherent layer (primary ASCs), the cells were detached using Trypsin-EDTA (0.05\% Trypsin-0.5 mM EDTA; Sigma-Aldrich, St. Louis MO, USA) for $3 \mathrm{~min}$, neutralized with the same volume of DMEM medium with 10\% (FBS, Gibco, Thermo Fisher Scientific), and centrifuged at $800 \mathrm{rpm}$ for $5 \mathrm{~min}$. The cells were expanded by successive passages, up to passage 5 .

When the targeted number of expanded ASCs was attained, the cells were detached from the culture vessel, thoroughly washed and suspended in DMEM. Aliquots were taken for cell counting, viability assay, microbiological testing, and MSC characterization. The expression of pluripotency factor Oct4 was detected by immunocytochemistry using a monoclonal antibody (Invitrogen).

\section{Flow cytometry immunophenotyping}

Phenotypic identification of the ASCs was performed with the use of conjugated monoclonal antibodies: Anti-canine CD90PE (VMRD, USA), anti-canine CD 105FITC (VMRD, USA), and anti-canine CD45PECy7 (VMRD, USA). Three hundred microliters of ASCs suspension containing 
200,000 cells were placed in Eppendorf tubes and incubated for $30 \mathrm{~min}$ at $4{ }^{\circ} \mathrm{C}$ with $15 \mu \mathrm{L}$ of monoclonal antibodies. Afterward, $500 \mu \mathrm{L}$ assay buffer (Millipore) and $300 \mu \mathrm{L}$ of flow count (Beckman Coulter) were added. A minimum of 10,000 events was acquired and analyzed with a Flujo Guava ${ }^{\circledR}$ easyCyte flow cytometer (Merck), and cytometry data were analyzed using Guava ${ }^{\circledR}$ InCyte ${ }^{\mathrm{TM}}$ software (Merck).

\section{Differentiation}

The multipotentiality of MSCs was determined by establishing the differentiation capacity in three lineages. For this purpose, ASCs $\left(5 \times 10^{3} / \mathrm{cm}^{2}\right)$ from the $5^{\text {th }}$ passage were cultured with DMEM-F12 medium with $10 \%$ FBS and $1 \%$ antibiotics (penicillin/streptomycin/amphotericin B) for $48 \mathrm{~h}$ at $37^{\circ} \mathrm{C}, 5 \% \mathrm{CO}_{2}$, and $95 \%$ humidity in 12 -well cell culture plates containing covers treated with poly-L-lysine $0.1 \%$ and sterilized by ultraviolet exposure for $12 \mathrm{~h}$.

\section{Osteogenic differentiation}

Osteogenesis differentiation medium (StemPro, Gibco) was used as per the manufacturer's instructions for osteogenic induction. ASCs were cultured for 21 days, the medium was changed every $3^{\text {rd }}$ day, and differentiation was assessed by Alizarin Red S (Sigma-Aldrich) staining, in which the cells were fixed with $4 \%$ formaldehyde solution for $30 \mathrm{~min}$ followed by rinsing with distilled water and staining with $2 \%$ Alizarin Red S solution ( $\mathrm{pH} 4.2$ ) for 2-3 min. Finally, the cells were rinsed with distilled water and visualized under a light microscope. Red staining indicates the deposition of bone mineral (calcium phosphate) by osteoblasts.

\section{Chondrogenic differentiation}

Chondrogenesis differentiation medium (StemPro, Gibco) was used as per the manufacturer's instructions for chondrogenic induction. ASCs were cultured for 14 days, the medium was changed every $3^{\text {rd }}$ day, and differentiation was assessed by Alcian blue staining. The cells were fixed with $4 \%$ formaldehyde for $30 \mathrm{~min}$ and then washed with PBS followed by the addition of $1 \%$ Alcian blue solution prepared in $0.1 \mathrm{~N} \mathrm{HCL}$ for $30 \mathrm{~min}$. Finally, the ASCs were washed with $0.1 \mathrm{~N} \mathrm{HCL}$ and distilled water was added. Blue staining indicates chondrocyte synthesis of proteoglycans. As a negative control, an equal number of cells were maintained in micromass culture supplemented with an expansion medium for up to 14 days.

\section{Adipogenic differentiation}

An adipogenesis differentiation kit (StemPro, Gibco) was used according to the manufacturer's instructions for adipogenic induction of the ASCs. The ASCs were cultured for 21 days; the medium was changed every $3^{\text {rd }}$ day, and differentiation was assessed by the presence of lipid droplets that were recorded after staining with Oil Red O stain. Red staining indicates the presence of lipids. As a negative control, an equal number of cells were maintained in the expansion medium for 21 days.

\section{Cryopreservation of ASCs}

Due to the design of the study (6 successive weekly doses), ASCs for injections underwent shortterm (up to 10 days) cryopreservation on liquid nitrogen. Cryopreservation was performed by adding a cryopreservation solution (DMEM containing 10\% FBS and 5\% dimethyl sulfoxide) at a dose of $5 \times 10^{6} \%$ cryovial. The resulting cell suspension was cryopreserved until the day of application to the patient, at which time the cells were rapidly thawed according to a previously described protocol [35] and suspended in $2 \mathrm{~mL}$ of physiological serum to be injected immediately. At this time, an aliquot was obtained to evaluate the number of cells, viability by means of the blue trypan solution which should be equal to or $>90 \%$ and microbiological culture.

\section{Injection of the cell product}

Following our routine practices for skin preparation and intramuscular injection in laboratory animals, $0.5 \times 10^{6}$ cells $/ \mathrm{kg}$ were intramuscularly injected weekly for 6 weeks into the dog's middle buttock. At the end of the treatment protocol ( $6^{\text {th }}$ week), each dog had received a total of $3.0 \times 10^{6}$ allogeneic ASCs cells $/ \mathrm{kg}$ at room temperature $\left(20-22^{\circ} \mathrm{C}\right)$.

\section{Study type, design, and patient population}

The clinical characteristics of the patients at baseline are shown in Figure-1. Feasibility in this work referred to the proportion of cells that survive cryo-freezing, after expanding the allogeneic ASCs ex vivo to reach a sufficient number of cells to obtain the multiple doses necessary for each patient after thawing, for 6 consecutive weeks.

To evaluate whether a stem cell treatment is safe, patients were monitored by both, physical examinations and laboratory tests, after treatment and during the study period. The absence of adverse events, graded according to the Veterinary cooperative oncology group-common terminology criteria for adverse events (VCOG-CTCAE) version 1.0 [36], was considered safety outcomes. An assessment of (1) local inflammation (heat, swelling, and function deterioration) in addition to the presence of new ulcers and worsening of existing ones; (2) systemic damage; and (3) any serious adverse events, leading to hospitalization or death was undertaken. At the same time, the

\begin{tabular}{|c|clccc|}
\hline Case $\neq$ & $\begin{array}{c}\text { Age / } \\
\text { months }\end{array}$ & Breed & $\begin{array}{c}\text { Weight / } \\
\boldsymbol{k g}\end{array}$ & $\begin{array}{c}\text { CADLI } \\
\text { score }\end{array}$ & $\begin{array}{c}\text { Pruritus } \\
\text { index }\end{array}$ \\
\hline 1 & 24 & Schnauzer 1 & 9,0 & 38 & 6 \\
2 & 18 & Pug 1 & 5,5 & 46 & 8 \\
3 & 14 & Labrador Retriever & 15,4 & 35 & 6 \\
4 & 12 & Schnauzer 2 & 11,5 & 42 & 6 \\
5 & 18 & Schnauzer 3 & 10,6 & 43 & 6 \\
6 & 15 & Pug 2 & 6,6 & 38 & 8 \\
7 & 18 & Pug 3 & 7,5 & 42 & 8 \\
8 & 12 & Schnauzer 4 & 8,0 & 42 & 8 \\
9 & 24 & Dachshund & 5,2 & 48 & 9 \\
10 & 18 & Jack Russell 1 & 7,3 & 39 & 8 \\
11 & 22 & Mongrel & 20,8 & 45 & 8 \\
12 & 13 & Jack Russell 2 & 6,5 & 40 & 6 \\
\hline
\end{tabular}

Figure-1: The clinical characteristics of the patients at baseline. 
clinical evidence of a decrease and/or absence of the most relevant initial characteristics related to atopic dermatitis and/or its comorbid conditions, recognized through the corresponding indexes were considered efficacies.

The dogs were evaluated for clinical lesions using the CAD Lesion Index (CADLI) and the pruritus index to record the extent and severity of lesions immediately before the pre-treatment and at 6 weeks of post-treatment.

The CADLI is a validated tool for the assessment of indicated body regions, integrating the severity and extent of the lesion(s) in a determined area. Scores from 0 (normal) to 5 (most severe) were obtained, yielding a final score of 0-50 based on the criteria established by plant [37]. To assess pruritis, the dog owners used the pruritus index which is a visual analog scale ranging from 0 (no pruritus) to 10 (extremely severe pruritus) including features of severity and behavior [38].

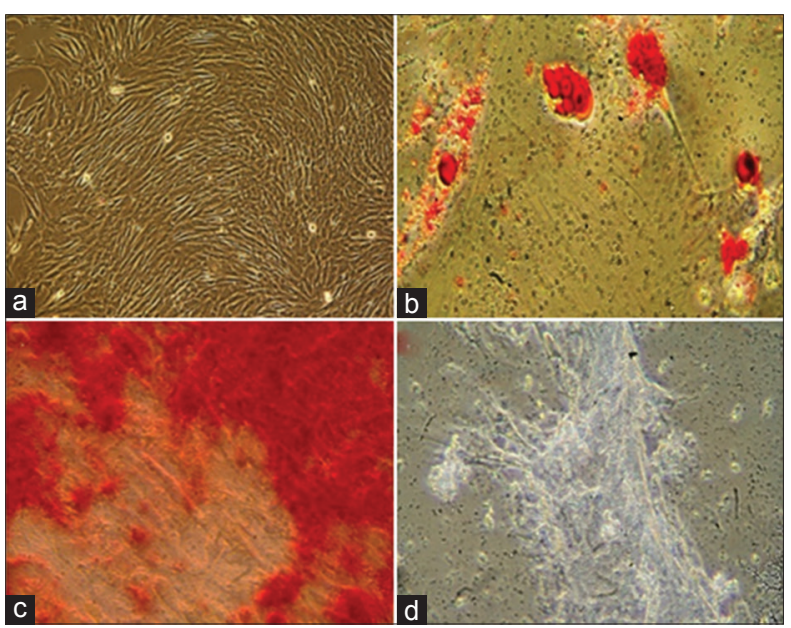

Figure-2: (a) Adipose tissue-derived canine mesenchymal stem cells (MSCs) from the $4^{\text {th }}$ passage showing a spindleshaped fibroblastic cell morphology. (b) After 3 weeks, adipose MSCs differentiated according to the conditioning medium added. Cells were stained with Oil Red $O$ staining for adipogenic. (c) Von Kossa staining for osteogenic. (d) Alcian blue staining for chondrogenic differentiation, $40 \times$.

\section{Blood chemistry and whole blood count}

Blood chemistry tests were performed to determine the levels of the following analytes: Glutamic oxaloacetic transaminase, glutamic pyruvic transaminase, alkaline phosphatase, urea, and creatinine using a biochemical analyzer (SINOWA, BS3100). The whole blood count was performed in a hematologic analyzer (Rayto RT-7600) at day 0 and at the end of treatment.

\section{Statistical analysis}

Data were expressed as the mean \pm standard deviation and the analyses were carried out using software programs (GraphPad Software, Inc., San Diego, California. United States). Shapiro-Wilk tests were used for testing the normality of data. The analysis of data was performed using the Wilcoxon test. Results were considered statistically significant when $p<0.05$.

\section{Results}

\section{Characteristics of the cell product for injection}

ASCs display a spindle-shaped morphology and a strong attachment to the surface of the culture vessel (Figure-2a). Population doubling time was $32 \mathrm{~h}$, which persisted during the whole expansion procedure.

Under proper stimuli, ex vivo expanded ASCs differentiated from the adipose (Figure-2b), osteo (Figure-2c), and cartilage (Figure-2d) linages. ASCs showed a homogeneous population of cells with high positive CD90 (94\%) and CD105 (92\%) expression and very low negative CD45 (0\%; Figure-3) expression and antigen Oct-4 (>90\%) expression by immunocytochemistry, the latter being a transcription factor critical for MSC pluripotency [39]. In addition, immediate post-thaw cell viability was $90 \%$.

\section{Procedural safety after cell injection}

There were no adverse events, clinically significant changes in the vitality signs or physical examination in relation to IM administration of allogeneic ASCs. No significant changes in laboratory test results were observed during the evaluation period. However,

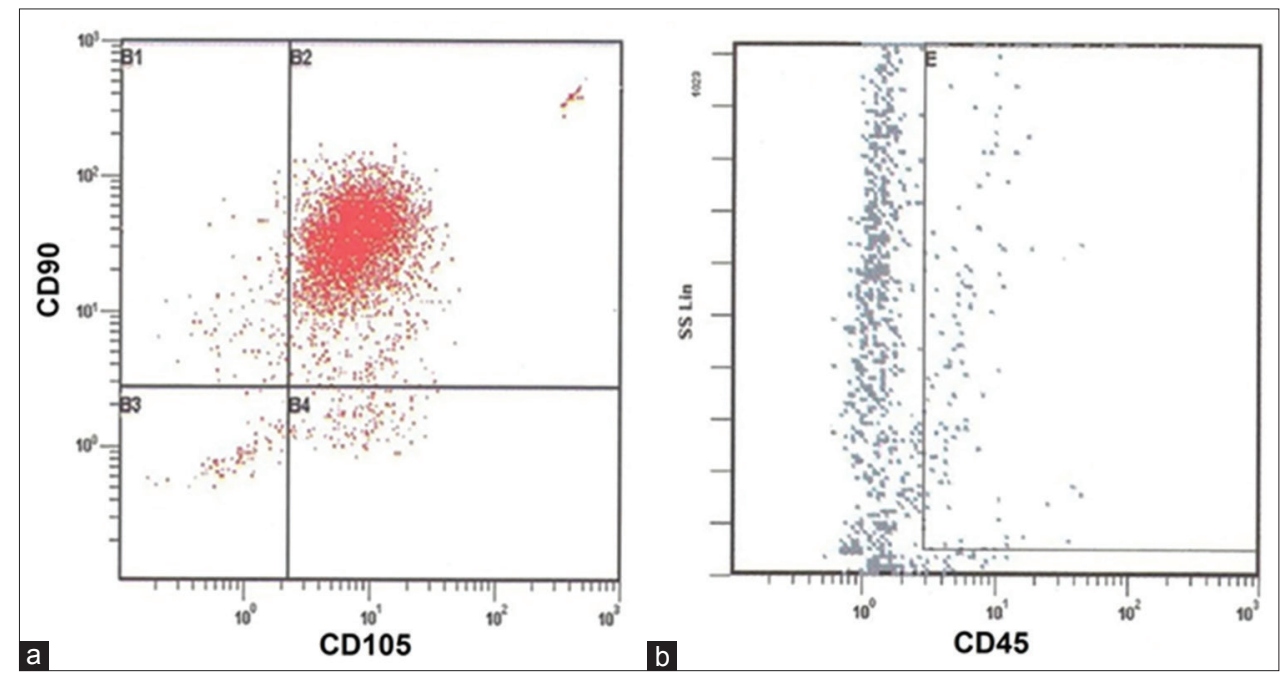

Figure-3: Flow cytometry of the adipose mesenchymal stem cell (MSC) population. Dot plots of adipose MSCs revealed (a) positive results for CD90 (94\%) and CD105 (92\%) and (b) were negative for CD45 (0\%). 
there was an increase in body weight at the end of the study period.

\section{Clinical assessment after ASCs injection}

Compared to baseline, it was found that the injection of the allogeneic cell product had eliminated and/or diminished most of the symptoms of the disease as well as associated comorbidities prevailing at inclusion, at 6 weeks after the initiation of the stem cell therapy (Figure-4).

In addition, CADLI scores and pruritus index obtained analyses showing statistically significant improvement post-therapy (Figure-5). The mean pre-treatment CADLI score was $41.50 \pm 3.729$, while the mean post-treatment score was $5.833 \pm 3.512$. This post-treatment improvement was statistically significant $(p<0.001)$. The mean pre-treatment value of
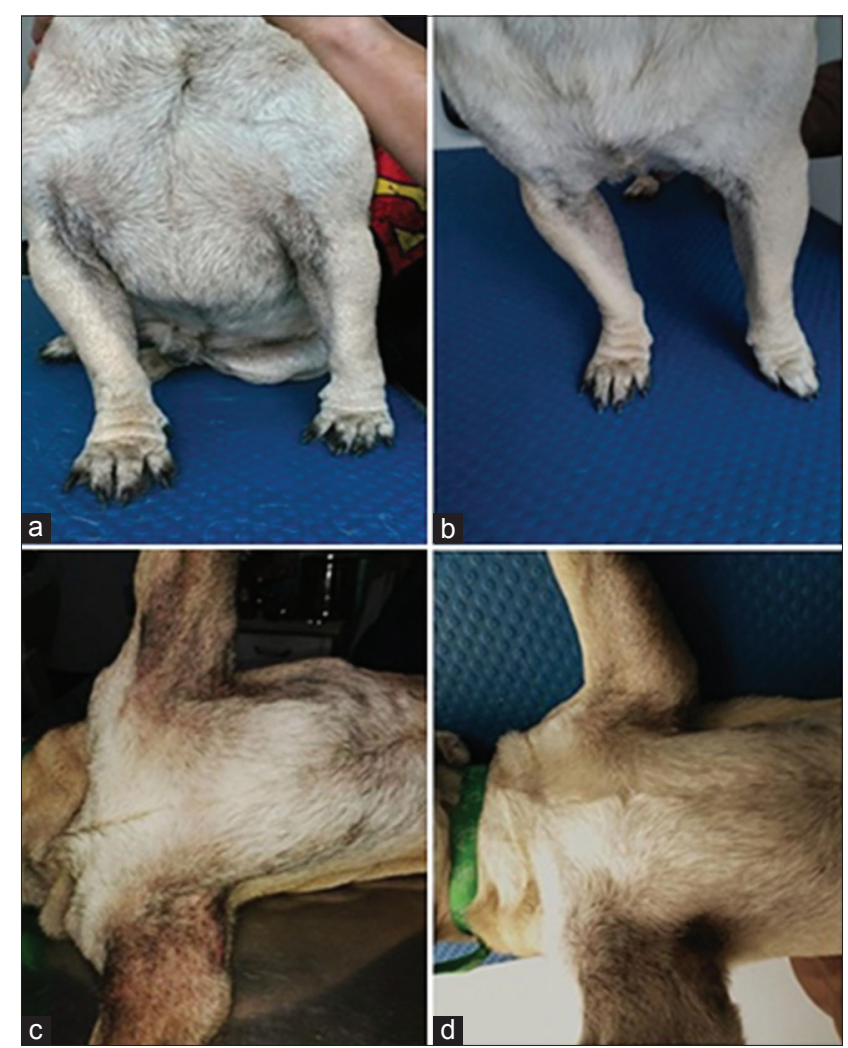

Figure-4: Case 2 ( $a$ and b), case 3 (c and d). a and c are pre-treatment and $b$ and $d$ were post-treatment. pruritus index was $7.250 \pm 1.138$, and the post-treatment value was $2.083 \pm 1.782$, showing a statistically significant improvement post-therapy $(\mathrm{p}<0.001)$. The mean pre-treatment value of weight was $9.492 \pm 4.582$, and the post-treatment value was $10.51 \pm 4.944$ showing a statistically significant improvement post-therapy $(\mathrm{p}<0.001)$ (Figure-6).

\section{Discussion}

In the present study, the intramuscular injection of six doses $\left(0.5 \times 10^{6}\right)$ of cryopreserved allogeneic ASCs proved to be safe and effective in the treatment of 12 dogs with atopic dermatitis. In all patients, a substantial reduction in pruritus and associated clinical symptoms of atopic dermatitis was observed shortly after injection. This effect of ASCs can be attributed to their previously described qualities including the modulation of Th1/Th2 response, which regulates the pro-inflammatory and pro-pruritic cytokines activated in acute atopic dermatitis $[16,40,41]$. These beneficial effects can also be related to other mechanisms of stem cell action such as inhibition of effector T-cell proliferation and the expression of inflammatory cytokines by expansion of regulatory T-cells and the production of interleukin-10 [42,43]. Moreover, the action of soluble ASCs factors [44-46] and/or the secretion of paracrine growth factors that can correct several pathophysiological alterations cannot be ruled out [47].

On review of the literature, we found no study on the use of the intramuscular route to apply stem cell therapy in dogs with atopic dermatitis. In addition, it is important to note that IM pathway is safe and minimally invasive alternative to conventional intravenous infusion; it also helps the prolonged survival of transplanted stem cells at the implant site, being a useful alternative to achieve clinical benefits $[36,48,49]$.

These results differ from a study in which allogeneic ASCs were intravenously injected at doses of 1.3 million cells/kg without diminishing the clinical signs of the disease [2]. However, another study carried out in 26 dogs with atopic dermatitis using an intravenous dose of $1.5 \times 10^{6} / \mathrm{kg}$ of live weight, achieved a reduction in the clinical lesions without adverse effects [50].

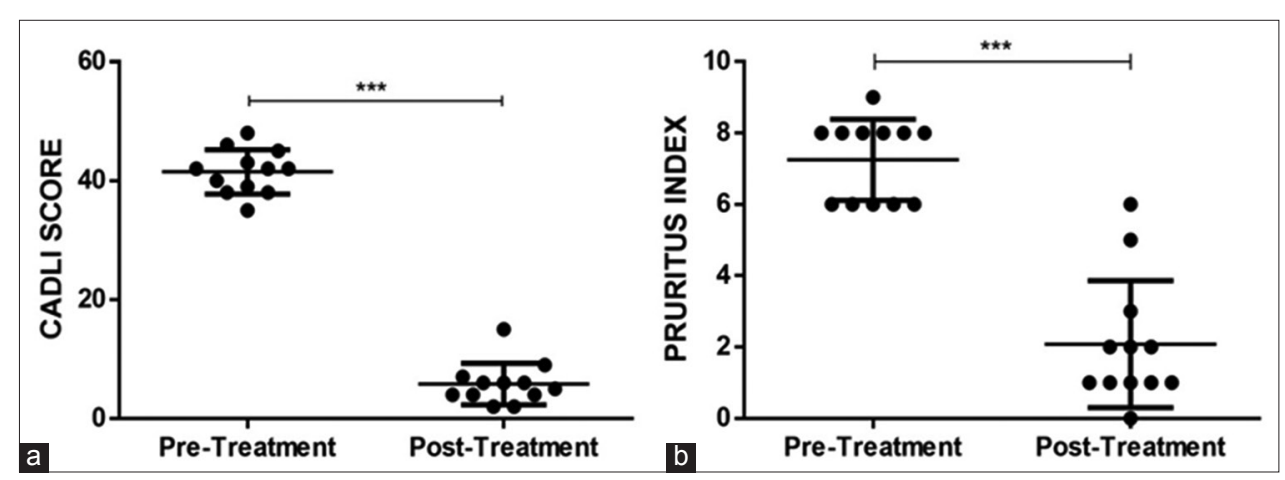

Figure-5: Effect of six doses of allogeneic stem cell therapy in dogs with atopic dermatitis according to the Canine Atopic Dermatitis Lesion Index score [37] and pruritus index [38]. Data represent mean \pm standard deviation. *** indicates a statistically significant difference of $p<0.001$. 


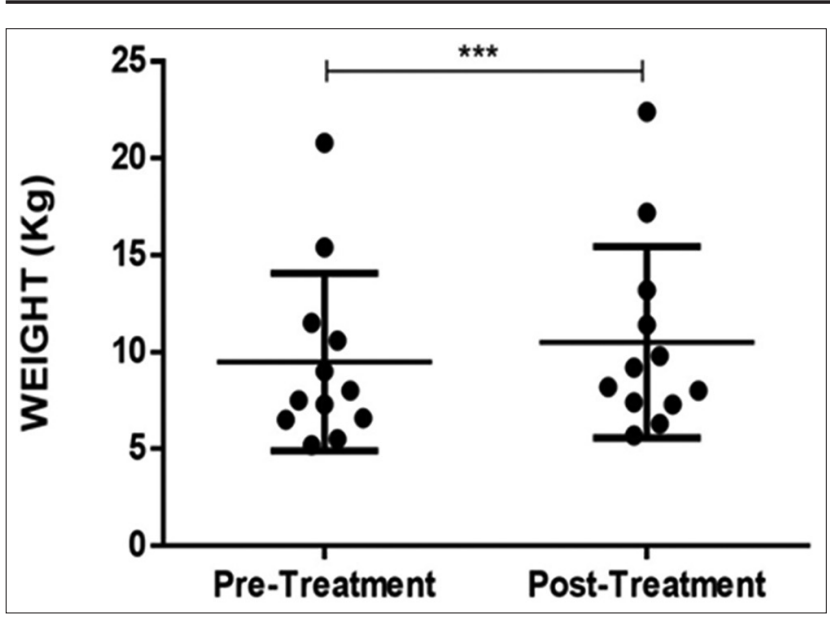

Figure-6: Weight of pre- and post-cellular therapy patients. Data represent mean \pm standard deviation. $* * *$ indicates a statistically significant difference of $p<0.001$.

Unlike the previously described studies, in the present study, we report a protocol of six low intramuscular doses of $0.5 \times 10^{6}$ of cryopreserved ASCs. The low doses reduce the risk of adverse effects induced by the intravenous administration of ASCs and cryopreservation diminishes the cost of production and facilitates immediate use after the diagnosis of atopic dermatitis. Indeed, some studies in animals and humans have shown that high doses of stem cells do not necessarily lead to better efficacy and have even suggested that they may have an inverse dose-response effect. Cell crowding is believed to play a role in this event [51].

It is of note that most of the dog owners recognized that they were grateful for the significant clinical improvements observed following the study after having been asked to report their satisfaction with the treatment. Although this study was not designed to evaluate the dose-response relationship, the clinical outcome revealed that the protocol used for the administration of the cell product (a similar weekly dose of ASCs for 6 weeks) was adequate to decrease skin lesions and itching. Other studies using different drugs for the treatment of atopic dermatitis have suggested that due to the multimodal nature of this pathology, it is necessary to establish the frequency and duration of treatment for each particular drug $[52,53]$.

The results of this clinical study show that the injection of allogeneic ASCs seems to be an effective treatment and a safe clinical approach for the treatment of CAD. These results are in contrast to those of other therapeutic approaches, which in many cases produce acute episodes of immunosuppression associated with systemic infections [54,55], urinary incontinence and lethargy [23], and/or a high risk of developing Cushing syndrome [22]. These results also suggest that trophic factors related to ASCs have regenerative properties.

\section{Conclusion}

The administration of multiple intramuscular doses of cryopreserved allogeneic ASCs to dogs with atopic dermatitis is a promising cellular therapeutic product for the relief of the symptoms of this disease. Nonetheless, the duration of the effects obtained with this dose should be compared with that of other doses, and the mechanism of action and possible long-term immunological reactions should be evaluated. As far as we know, this is the first report on the use of multiple intramuscular doses of cryopreserved allogeneic ASCs to treat atopic dermatitis.

\section{Authors' Contributions}

JE designed and performed the study. NE contributed in collecting data, interpretation of data, and writing the manuscript. JP and JA participated in collecting data and interpretation of data. JE write and revised the manuscripts. All authors read and approved the final manuscript.

\section{Acknowledgments}

This work was funded by Consejo Nacional de Ciencia y Tecnologia del Peru, Grant No. 409-2012 and INNOVATEPERU $\mathrm{N}^{\circ}$ 168-FINCYT-FIDECOMPIMEN-2013 and $\mathrm{N}^{\circ}$ 541-FIDECOM-INNOVATE PERÚ-PIMEN-2015.

\section{Competing Interests}

The authors declare that they have no competing interests.

\section{Publisher's Note}

Veterinary World remains neutral with regard to jurisdictional claims in published institutional affiliation.

\section{References}

1. Hall, M.N., Rosenkrantz, W.S., Hong, J.H., Griffin, C.E. and Mendelsohn, C.M. (2010) Evaluation of the potential use of adipose-derived mesenchymal stromal cells in the treatment of canine atopic dermatitis: A pilot study. Vet Ther., 11(2): E1-14.

2. Hensel, P., Santoro, D., Favrot, C., Hill, P. and Griffin, C. (2015) Canine atopic dermatitis: Detailed guidelines for diagnosis and allergen identification. BMC Vet. Res., 11: 196.

3. Marsella, R. and De Benedetto, A. (2017) Atopic dermatitis in animals and people: An update and comparative review. Vet. Sci., 4(3): E37.

4. Peng, W. and Novak, N. (2015) Pathogenesis of atopic dermatitis. Clin Exp Allergy, 45(3): 566-574.

5. Gedon, N.K.Y. and Mueller, R.S. (2018) Atopic dermatitis in cats and dogs: A difficult disease for animals and owners. Clin. Transl. Allergy, 8: 41.

6. DeBoer, D.J. and Griffin, C.E. (2001) The ACVD task force on canine atopic dermatitis (8I): Antihistamine pharmacotherapy. Vet. Immunol. Immunopathol., 81(3-4): 323-329.

7. Nuttall, T., Uri, M. and Halliwell, R. (2013) Canine atopic dermatitis what have we learned? Vet. Rec., 172(8): 201-207.

8. Bradley, C.W., Morris, D.O., Rankin, S.C., Cain, C.L., Misic, A.M., Houser, T., Mauldin, E.A. and Grice, E.A. (2016) Longitudinal evaluation of the skin microbiome and association with microenvironment and treatment in canine atopic dermatitis. J. Invest. Dermatol., 136(6): 1182-1190.

9. Hoskova, Z., Svoboda, M., Satinska, D., Matiasovic, J., Leva, I. and Toman, M. (2015) Changes in leukocyte counts, lymphocyte subpopulations and the mRNA expression of selected cytokines in the peripheral blood of dogs 
with atopic dermatitis. Vet. Med., 60(11): 644-653.

10. Werfel, T., Allam, J.P., Biedermann, T., Eyerich, K., Gilles, S., Guttman-Yassky, E., Hoetzenecker, W., Knol, E., Simon, H.U., Wollenberg, A., Bieber, T., Lauener, R., Schmid-Grendelmeier, P., Traidl-Hoffmann, C. and Akdis, C.A. (2016) Cellular and molecular immunologic mechanisms in patients with atopic dermatitis. $J$. Allergy Clin. Immunol., 138(2): 336-349.

11. Brunner, P.M., Guttman-Yassky, E. and Leung, D.Y. (2017) The immunology of atopic dermatitis and its reversibility with broad-spectrum and targeted therapies. J. Allergy Clin. Immunol., 139(4S): S65-S76.

12. Asahina, R. and Maeda, S. (2017) A review of the roles of keratinocyte-derived cytokines and chemokines in the pathogenesis of atopic dermatitis in humans and dogs. Vet. Dermatol., 28(1): 16-e5.

13. Favrot, C., Steffan, J., Seewald, W. and Picco, F. (2010) A prospective study on the clinical features of chronic canine atopic dermatitis and its diagnosis. Vet. Dermatol., 21(1): 23-31.

14. Olivry, T., DeBoer, D.J., Favrot, C., Jackson, H.A., Mueller, R.S., Nuttall, T., Prélaud, P. and International Task Force on Canine Atopic Dermatitis. (2010) Treatment of canine atopic dermatitis: 2010 clinical practice guidelines from the international task force on canine atopic dermatitis. Vet Dermatol., 21(3): 233-248.

15. Blaskovic, M., Rosenkrantz, W., Neuber, A., Sauter-Louis, C. and Mueller, R.S. (2014) The effect of a spot-on formulation containing polyunsaturated fatty acids and essential oils on dogs with atopic dermatitis. Vet. J., 199(1): 39-43.

16. Gonzales, A.J., Fleck, T.J., Humphrey, W.R., Galvan, B.A., Aleo, M.M., Mahabir, S.P., Tena, J.K., Greenwood, K.G. and McCall, R.B. (2016) IL-31-induced pruritus in dogs: A novel experimental model to evaluate anti-pruritic effects of canine therapeutics. Vet. Dermatol., 27(1): 34-e10.

17. Plant, J.D. and Neradilek, M.B. (2017) Effectiveness of regionally-specific immunotherapy for the management of canine atopic dermatitis. BMC Vet Res., 13(1): 4.

18. Jee, M.K., Im, Y.B., Choi, J.I. and Kang, S.K. (2013) Compensation of cATSCs-derived TGFbetal and IL10 expressions was effectively modulated atopic dermatitis. Cell. Death Dis., 4: e497.

19. DeBoer, D.J. (2017) The future of immunotherapy for canine atopic dermatitis: A review. Vet. Dermatol., 28(1): 25-e6.

20. Spergel, J.M. (2008) Immunology and treatment of atopic dermatitis. Am. J. Clin. Dermatol., 9(4): 233-244.

21. Olivry, T. and Banovic, F. (2019) Treatment of canine atopic dermatitis: Time to revise our strategy? Vet. Dermatol., 30(2): 87-90.

22. Behrend, E.N. and Kemppainen, R.J. (1997) Glucocorticoid therapy. pharmacology, indications, and complications. Vet. Clin. North Am. Small Anim. Pract., 27(2): 187-213.

23. Dip, R., Carmichael, J., Letellier, I., Strehlau, G., Roberts, E., Bensignor, E. and Rosenkrantz, W. (2013) Concurrent short-term use of prednisolone with cyclosporine $\mathrm{A}$ accelerates pruritus reduction and improvement in clinical scoring in dogs with atopic dermatitis. BMC Vet. Res., 9: 173.

24. Strioga, M., Viswanathan, S., Darinskas, A., Slaby, O. and Michalek, J. (2012) Same or not the same? Comparison of adipose tissue-derived versus bone marrow-derived mesenchymal stem and stromal cells. Stem Cells Dev., 21(14): 2724-2752.

25. Ra, J.C., Jeong, E.C., Kang, S.K., Lee, S.J. and Choi, K.H. (2017) A prospective, nonrandomized, no placebo-controlled, phase I/II clinical trial assessing the safety and efficacy of intramuscular injection of autologous adipose tissue-derived mesenchymal stem cells in patients with severe buerger's disease. Cell. Med., 9(3): 87-102.

26. Escalhao, C.C.M., Ramos, I.P., Hochman-Mendez, C., Brunswick, T.H.K., Souza, S.A.L., Gutfilen, B., Dos Santos
Goldenberg, R.C. and Coelho-Sampaio, T. (2017) Safety of allogeneic canine adipose tissue-derived mesenchymal stem cell intraspinal transplantation in dogs with chronic spinal cord injury. Stem Cells Int., 2017: Article ID 3053759.

27. Petchdee, S. and Sompeewong, S. (2016) Intravenous administration of puppy deciduous teeth stem cells in degenerative valve disease. Vet. World, 9(12): 1429-1434.

28. Zhang, Y., Meng, Q., Zhang, Y., Chen, X. and Wang, Y. (2017) Adipose-derived mesenchymal stem cells suppress of acute rejection in small bowel transplantation. Saudi $J$. Gastroenterol., 23(6): 323-329.

29. Ivanova-Todorova, E., Bochev, I., Mourdjeva, M., Dimitrov, R., Bukarev, D., Kyurkchiev, S., Tivchev, P., Altunkova, I. and Kyurkchiev, D.S. (2009) Adipose tissue-derived mesenchymal stem cells are more potent suppressors of dendritic cells differentiation compared to bone marrow-derived mesenchymal stem cells. Immunol. Lett., 126(1-2): 37-42.

30. Crop, M.J., Baan, C.C., Korevaar, S.S., Ijzermans, J.N., Weimar, W. and Hoogduijn, M.J. (2010) Human adipose tissue-derived mesenchymal stem cells induce explosive T-cell proliferation. Stem Cells Dev., 19(12): 1843-1853.

31. Hegyi, B., Kudlik, G., Monostori, E. and Uher, F. (2012) Activated T-cells and pro-inflammatory cytokines differentially regulate prostaglandin E2 secretion by mesenchymal stem cells. Biochem. Biophys. Res. Commun., 419(2): 215-220.

32. Ribeiro, A., Laranjeira, P., Mendes, S., Velada, I., Leite, C., Andrade, P., Santos, F., Henriques, A., Grãos, M., Cardoso, C.M., Martinho, A., Pais, M., da Silva, C.L., Cabral, J., Trindade, H. and Paiva, A. (2013) Mesenchymal stem cells from umbilical cord matrix, adipose tissue and bone marrow exhibit different capability to suppress peripheral blood B, natural killer and T cells. Stem Cell Res. Ther., 4(5): 125.

33. Domenis, R., Cifu, A., Quaglia, S., Pistis, C., Moretti, M., Vicario, A., Parodi, P.C., Fabris, M., Niazi, K.R., SoonShiong, P. and Curcio, F. (2018) Pro inflammatory stimuli enhance the immunosuppressive functions of adipose mesenchymal stem cells-derived exosomes. Sci. Rep., 8(1): 13325.

34. Bunnell, B.A., Flaat, M., Gagliardi, C., Patel, B. and Ripoll, C. (2008) Adipose-derived stem cells: Isolation, expansion and differentiation. Methods, 45(2): 115-120.

35. Mitchell, A., Rivas, K.A., Smith, R. and Watts, A.E. (2015) Cryopreservation of equine mesenchymal stem cells in $95 \%$ autologous serum and 5\% DMSO does not alter post-thaw growth or morphology in vitro compared to fetal bovine serum or allogeneic serum at 20 or $95 \%$ and DMSO at 10 or 5. Stem Cell Res. Ther., 6: 231.

36. VCOG (2004) Veterinary co-operative oncology group common terminology criteria for adverse events (VCOGCTCAE) following chemotherapy or biological antineoplastic therapy in dogs and cats v1.0. Vet. Comp. Oncol., 2(4): 195-213.

37. Plant, J.D., Gortel, K., Kovalik, M., Polissar, N.L. and Neradilek, M.B. (2012) Development and validation of the Canine Atopic Dermatitis Lesion Index, a scale for the rapid scoring of lesion severity in canine atopic dermatitis. Vet. Dermatol., 23(6): 515-e103.

38. Hill, P.B., Lau, P. and Rybnicek, J. (2007) Development of an owner-assessed scale to measure the severity of pruritus in dogs. Vet. Dermatol., 18(5): 301-308.

39. Pan, G.J., Chang, Z.Y., Scholer, H.R. and Pei, D. (2002) Stem cell pluripotency and transcription factor Oct4. Cell Res., 12(5-6): 321-329.

40. Olivry, T., Mayhew, D., Paps, J.S., Linder, K.E., Peredo, C., Rajpal, D., Hofland, H. and Cote-Sierra, J. (2016) Early activation of Th2/Th22 inflammatory and pruritogenic pathways in acute canine atopic dermatitis skin lesions. $J$. Invest. Dermatol., 136(10): 1961-1969.

41. Orciani, M., Campanati, A., Caffarini, M., Ganzetti, G., Consales, V., Lucarini, G., Offidani, A. and Di Primio, R. (2017) T helper (Th)1, Th17 and Th2 
imbalance in mesenchymal stem cells of adult patients with atopic dermatitis: At the origin of the problem. $B r . J$. Dermatol., 176(6): 1569-1576.

42. Jeong, S.B., Jienny, L., Do Hyung, K., Gyeong-Been, L., Hee-Ryang, K., Na-Yeon, G., Cho, I.S. and Cha, S.H. (2016) Canine mesenchymal stem cells immunomodulate atopic dermatitis through the induction of regulatory $\mathrm{T}$ cells in an ex vivo experimental study. J. Prev. Vet. Med., 40(1): 12-21.

43. Zhang, L., Wang, X.Y., Zhou, P.J., He, Z., Yan, H.Z., Xu, D.D., Wang, Y., Fu, W,Y., Ruan, B.B., Wang, S., Chen, H.X., Liu, Q.Y., Zhang, Y.X., Liu, Z. and Wang, Y.F. (2017) Use of immune modulation by human adipose-derived mesenchymal stem cells to treat experimental arthritis in mice. Am. J. Transl. Res., 9(5): 2595-2607.

44. Gonzalez, M.A., Gonzalez-Rey, E., Rico, L., Buscher, D. and Delgado, M. (2009) Adipose-derived mesenchymal stem cells alleviate experimental colitis by inhibiting inflammatory and autoimmune responses. Gastroenterology, 136(3): 978-989.

45. McIntosh, K.R., Frazier, T., Rowan, B.G. and Gimble, J.M. (2013) Evolution and future prospects of adipose-derived immunomodulatory cell therapeutics. Expert Rev. Clin. Immunol., 9(2): 175-184.

46. Bahamondes, F., Flores, E., Cattaneo, G., Bruna, F. and Conget, P. (2017) Omental adipose tissue is a more suitable source of canine mesenchymal stem cells. BMC Vet. Res., 13(1): 166.

47. Miana, V.V. and Gonzalez, E.A.P. (2018) Adipose tissue stem cells in regenerative medicine. Ecancermedicalscience, 12: 822 .

48. van Rhijn-Brouwer, F.C.C., Gremmels, H., Fledderus, J.O., Schuurman, A.H., Bonte-Mineur, F., Vonk, M.C., Voskuyl, A.E., de Vries-Bouwstra, J.K., Coert, J.H., Radstake, T.R.D., van Laar, J.M., Verhaar, M.C. and MANUS Study Group. (2018) A randomised placebo-controlled double-blind trial to assess the safety of intramuscular administration of allogeneic mesenchymal stromal cells for digital ulcers in systemic sclerosis: The
MANUS Trial protocol. BMJ Open., 8(8): e020479.

49. Braid, L.R., Wood, C.A., Wiese, D.M. and Ford, B.N. (2018) Intramuscular administration potentiates extended dwell time of mesenchymal stromal cells compared to other routes. Cytotherapy, 20(2): 232-244.

50. Villatoro, A.J., Hermida-Prieto, M., Fernandez, V., Farinas, F., Alcoholado, C., Rodriguez-Garcia, M.I., Mariñas-Pardo, L. and Becerra, J. (2018) Allogeneic adipose-derived mesenchymal stem cell therapy in dogs with refractory atopic dermatitis: Clinical efficacy and safety. Vet. Rec., 183(21): 654.

51. Hare, J.M., Fishman, J.E., Gerstenblith, G., Velazquez, D.L.D., Zambrano, J.P., Suncion, V.Y., Tracy, M., Ghersin, E., Johnston, P.V., Brinker, J.A., Breton, E., DavisSproul, J., Schulman, I.H., Byrnes, J., Mendizabal, A.M., Lowery, M.H., Rouy, D., Altman, P., Foo, C.W.P., Ruiz, P., Amador, A., Da Silva, J., McNiece, I.K., Heldman, A.W., George, R. and Lardo, A. (2012) Comparison of allogeneic vs autologous bone marrow-derived mesenchymal stem cells delivered by transendocardial injection in patients with ischemic cardiomyopathy: The POSEIDON randomized trial. JAMA, 308(22): 2369-2379.

52. Piekutowska, A., Pin, D., Reme, C.A., Gatto, H. and Haftek, M. (2008) Effects of a topically applied preparation of epidermal lipids on the stratum corneum barrier of atopic dogs. J. Comp. Pathol., 138(4): 197-203.

53. Popa, I., Remoue, N., Osta, B., Pin, D., Gatto, H., Haftek, M. and Portoukalian, J. (2012) The lipid alterations in the stratum corneum of dogs with atopic dermatitis are alleviated by topical application of a sphingolipid-containing emulsion. Clin. Exp. Dermatol., 37(6): 665-6671.

54. Ihrke, P.J., Norton, A.L., Ling, G.V. and Stannard, A.A. (1985) Urinary tract infection associated with long-term corticosteroid administration in dogs with chronic skin diseases. J. Am. Vet. Med. Assoc., 186(1): 43-46.

55. Nuttall, T., Reece, D. and Roberts, E. (2014) Life-long diseases need life-long treatment: Long-term safety of ciclosporin in canine atopic dermatitis. Vet. Rec., 174(Suppl 2): 3-12.

$* * * * * * * *$ 